\title{
Drug utilization study in patients of COPD in TB and Chest department in a tertiary care teaching hospital
}

\author{
Abhishek Y. Vyas*, Gurusharan H. Dumra, A. J. Singh
}

Department of Pharmacology, AMC MET Medical College, Maninagar, Ahmedabad 380008, Gujarat, India

Received: 23 March 2017
Accepted: 22 April 2017

*Correspondence to:

Dr. Abhishek Y. Vyas, Email: vyas2611@gmail.com

Copyright: (C) the author(s), publisher and licensee Medip Academy. This is an openaccess article distributed under the terms of the Creative Commons Attribution NonCommercial License, which permits unrestricted noncommercial use, distribution, and reproduction in any medium, provided the original work is properly cited.

\begin{abstract}
Background: Chronic Obstructive Pulmonary Disease (COPD) is a major cause of chronic morbidity and mortality throughout the world. It is the fourth leading cause of death in the world, and further increase in its prevalence and mortality can be predicted in the coming decades. Many people die prematurely from it or its complications. Total deaths from COPD are projected to increase by more than $30 \%$ in the next 10 years unless urgent action is taken to reduce the underlying risk factors, especially tobacco use. Estimates show that in 2020 COPD will become the third leading cause of death worldwide. A wide range of drugs are prescribed for COPD but not strictly according to established guidelines.

Methods: A prospective observational study of drugs prescribed in COPD was conducted in outdoor patients at TB and Chest department at Sheth L. G. General Hospital.

Results: Total 90 prescriptions of COPD patient were collected and studied for drug utilization. The results revealed that the ratio of prevalence in males was higher than females, which was $73 \%$ and $27 \%$ respectively. Theophylline (93.3\%) and chlorpheniramine $(71.1 \%)$ were most prescribed drugs.

Conclusions: According to the results, prevalence was higher in males than females and was higher in smokers than nonsmokers and most common prescribed class of drug was methylxanthine.
\end{abstract}

Keywords: Chronic obstructive pulmonary disease, Drug utilization, Triple inhaled therapy

\section{INTRODUCTION}

Chronic obstructive pulmonary disease (COPD) is a lung disease characterized by chronic obstruction of lung airflow that interferes with normal breathing and is not fully reversible. COPD is the fourth leading cause of death in the world, and further increase in its prevalence and mortality can be predicted in the coming decades. ${ }^{1,2}$ Total deaths from COPD are projected to increase by more than $30 \%$ in the next 10 years unless urgent action is taken to reduce the underlying risk factors, especially tobacco use. Estimates show that in 2020 COPD will become the third leading cause of death worldwide. ${ }^{3}$ COPD is not simply a "smoker's cough" but an underdiagnosed, life-threatening lung disease. ${ }^{4}$

Tobacco smoking continues to be a major cause of COPD, as well as of many other diseases. However, tobacco smoking is not the only cause of COPD, and it may not even be the major cause in some parts of the world. Furthermore, not all smokers develop clinically significant COPD, which suggests that additional factors are involved in determining each individual's susceptibility. ${ }^{5}$

Treatment guidelines for COPD are based on GOLD 2017 Guidelines. These are as under:

\section{Long-acting bronchodilators}

Almost all patients with COPD who experience more than occasional dyspnea should be prescribed long acting bronchodilator therapy. This could be a long-acting beta agonist (LABA), a long acting muscarinic antagonist (LAMA), or both. Patients with persistent COPD symptoms while taking one long-acting bronchodilator 
should be prescribed two (or a combination agent containing two long acting bronchodilators).

\section{Inhaled corticosteroids}

Inhaled corticosteroids are not recommended as monotherapy in COPD. Combination agents containing inhaled corticosteroids along with long-acting beta agonists are considered appropriate step-up therapy for patients experiencing COPD exacerbations while taking long-acting bronchodilators.

\section{Oral PDE4 inhibitors}

Oral PDE4 inhibitors are considered an add-on therapy only for patients with COPD with chronic bronchitis and severe airflow restriction who experience COPD exacerbations despite use of a combination bronchodilator with inhaled corticosteroid. The 2017 GOLD guidelines go further in advising physicians exactly what class of medication to use, in which COPD patients according to where they fall in the ABCD grading scheme:

\section{COPD GOLD Grade A}

Any bronchodilator (short or long acting), titrating or switching to another as appropriate.

\section{COPD GOLD Grade B}

A long acting bronchodilator (LAMA or LABA), and both if symptoms persist on one drug.

\section{COPD GOLD Grade C}

A long acting muscarinic antagonist (LAMA), switching to LAMA+LABA or to LABA+ICS if further exacerbations occur.

\section{COPD GOLD Grade D}

More complicated, requires individual management, often multiple drugs, consideration of roflumilast and azithromycin in selected patients. Inhaler technique should be demonstrated for all patients and technique confirmed before concluding a medication is not working.

\section{METHODS}

That was a prospective observational study. Period of the study was 6 months.

\section{Study population}

The study group consists of 90 patients, either sex, diagnosed with COPD at Sheth L. G. Hospital. Maninagar, Ahmedabad.

\section{Inclusion criteria}

- Patients of either sex, aged $\geq 18$ years

- Patients who diagnosed COPD along with or without co-morbidities

- Smokers

- Willing to give consent

\section{Procedure}

A prospective observational study was conducted in Tertiary Care Teaching and Research Hospital, Ahmedabad, India. The Institutional Ethics Committee (IEC) approval was taken before conducting the study. The patients who satisfied the study inclusion criteria were enrolled in the study after taking Informed Consent (IC). The clinical, demographic and medication data was documented into case report form (CRF).

\section{RESULTS}

Total 90 prescriptions were collected. Total numbers of female patients were 24 and male patients were 66 , which is $26 \%$ and $73 \%$ respectively (Figure 1 ).

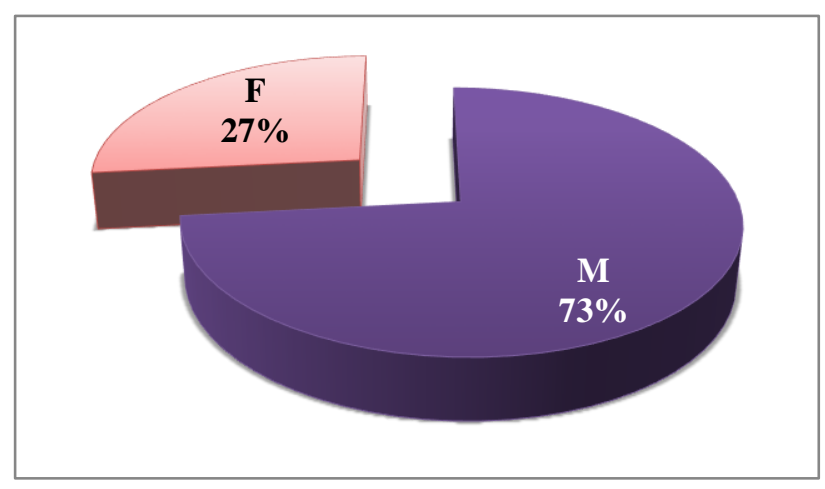

Figure 1: Gender wise distribution of COPD.

It has been observed that $56 \%$ patients were smokers (Figure 2). Furthermore, among those $56 \%$ of smokers, $28.88 \%$ patients were current smokers and $26.66 \%$ had past history of smoking.

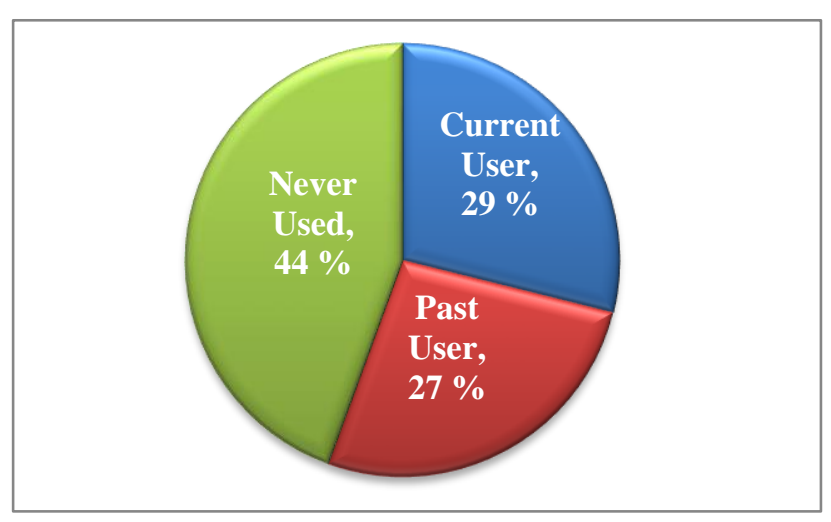

Figure 2: Smoking history. 
$44.44 \%$ patients never smoked. The highest number of patients was from age group of 56-60 years, which was $31.1 \%$ and lowest number of patients was from age group of 26-30 years, which was $2.2 \%$ (Figure 3 ).

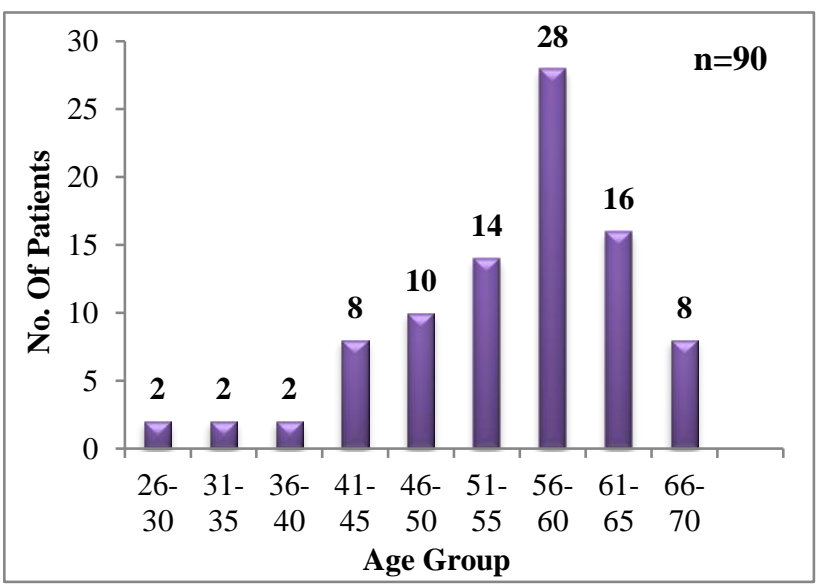

Figure 3: Age wise distribution of COPD patients.

In present study $44.4 \%$ of patients were with co-morbid conditions, in which top of the list was Hypertension followed by Diabetes Mellitus type 2 and Pulmonary Tuberculosis (Table 1).

Among 90 prescription observed, $51.1 \%$ patients had been prescribed 4 drugs and $31.1 \%$ prescribed 3 drugs (Figure 4).

Among the drugs prescribed for COPD, theophylline was prescribed most frequently $(93.3 \%)$. Second most commonly prescribed drug was Chlorpheniramine $(71.1 \%)$.

In fixed dose combination therapy, most frequently prescribed one was Formoterol+Tiotropium+Ciclesonide $40 \%$. Among non COPD drugs, omeprazole was prescribed $51.1 \%$ (Figure 5).
Table 1: Demographic parameter.

\begin{tabular}{|c|c|}
\hline & Demographic parameter \\
\hline \multirow{2}{*}{ 1. Gender } & Male: $73.33 \%$ \\
\hline & Female: $26.66 \%$ \\
\hline \multirow{9}{*}{ 2. Age } & $26-30: 2.22 \%$ \\
\hline & $31-35: 2.22 \%$ \\
\hline & $36-40: 2.22 \%$ \\
\hline & $41-45: 8.88 \%$ \\
\hline & 46-50: $11.11 \%$ \\
\hline & 51-55: $15.55 \%$ \\
\hline & 56-60: $31.11 \%$ \\
\hline & 61-65: $17.77 \%$ \\
\hline & $66-70: 8.88 \%$ \\
\hline \multirow{3}{*}{$\begin{array}{l}\text { 3. Smoking } \\
\text { history }\end{array}$} & Never used: $44.44 \%$ \\
\hline & Current user: $28.88 \%$ \\
\hline & Past user: $26.66 \%$ \\
\hline \multirow{6}{*}{$\begin{array}{l}\text { 4. Co- } \\
\text { morbidities }\end{array}$} & Fibrotic Pulmonary TB: $4.44 \%$ \\
\hline & Diabetes mellitus Type II: $8.89 \%$ \\
\hline & Hypertension: $13.33 \%$ \\
\hline & Pulmonary Tuberculosis: $8.89 \%$ \\
\hline & Systemic Sclerosis: $2.22 \%$ \\
\hline & $\begin{array}{l}\text { Past history of Pulmonary TB: } \\
6.67 \%\end{array}$ \\
\hline
\end{tabular}

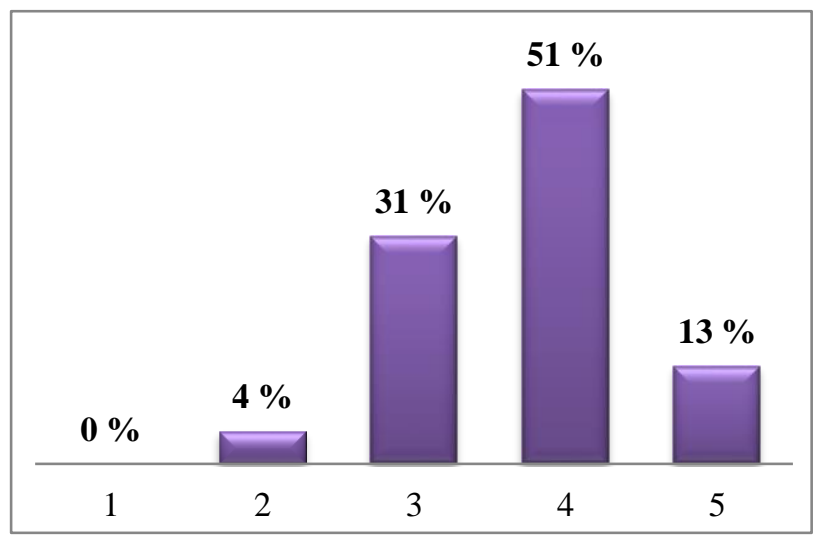

Figure 4: No. of drugs prescribed per prescription.

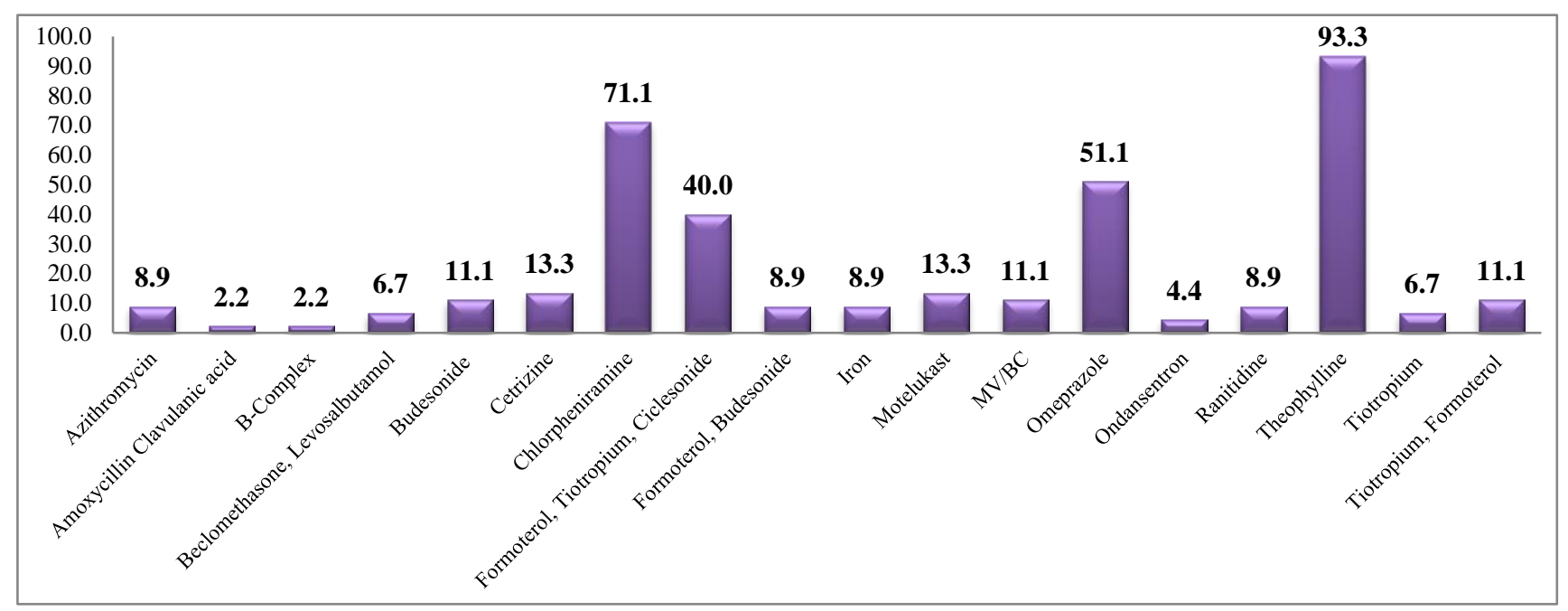

Figure 5: Percentage of prescribed drugs. 
Most commonly prescribed fixed dose combination therapy of drugs was Formoterol+ Tiotropium+ Ciclesonide $40 \%$ followed by Formoterol+ Budesonide and Beclomethasone+ Levosalbutamol which was $8.9 \%$ and $6.7 \%$ respectively.

\section{DISCUSSION}

Drug utilization research is an essential part of pharmacoepidemiology as it describes the extent, nature and determinants of drug exposure. Large population suffers from COPD, hence it is very essential to spread a thorough awareness among patients in relation to medication and disease itself. Evaluation of drug utilization pattern in COPD will provide a powerful tool for the same.

Majority of the patients in the present study had comorbid conditions $(n=40 ; 44.4 \%)$. The most commonly observed co-morbid conditions were hypertension (13.33\%) and Type II diabetes mellitus (8.89\%).

Concerning the gender wise distribution, majority of the patients were males which is $73.33 \%$. The females accounted for around $26.66 \%$. Male to Female ratio was around $3: 1$. These findings were almost similar to the result of previous study in which male patients were $87 \%$ and female patients were $12 \% .^{6}$

A systemic review of RCT found that the ipratropium bromide alone provided small benefit over short acting $\beta 2$ agonist in terms of lung function, health status and requirement of oral steroids. ${ }^{7}$ In present study no patients were prescribed ipratropium alone or in combination.

Triple inhaled therapy ( $\beta 2$ agonist, anticholinergic and inhaled corticosteroid) may improve lung function and patient reported outcomes. In present study triple inhaled therapy was Formoterol, Tiotropium and Ciclesonide which was prescribed in $40 \%$ of patients and it is according to GOLD COPD guideline. ${ }^{7}$

\section{CONCLUSION}

Drug utilization in COPD was evaluated in patients who attended the OPD of TB and Chest at Sheth L. G. General Hospital. The results suggest that prevalence was higher in males than females and was higher in smokers than nonsmokers. Most common prescribed class of drug was methylxanthine (Theophylline 93.3\%). Despite the use of drugs according to the availability, it was found in the analysis that majority were in accordance with GOLD criteria recommendations.

\section{ACKNOWLEDGMENTS}

This study was carried out with assistance from Department of TB and Chest, Sheth L. G. General Hospital, Maninagar. Ahmedabad, Gujarat, India.

Funding: No funding sources

Conflict of interest: None declared

Ethical approval: The study was approved by the Institutional Ethics Committee

\section{REFERENCES}

1. World Health Report. Geneva: World Health Organization. Available from URL: http://www.who.int/whr/2000/en/statistics.htm; 2000

2. Lopez AD, Shibuya K, Rao C, Mathers CD, Hansell AL, Held LS, et al. Chronic obstructive pulmonary disease: current burden and future projections. Eur Respir J. 2006;27(2):397-412.

3. Institute for Health and Clinical Excellence, chronic obstructive pulmonary disease, management of chronic obstructive pulmonary disease in adults in primary and secondary care (partial update), NICE 2010. Available from: http://www.nice.org.uk/. [Last accessed on 2010 Aug 14].

4. World Health Organization. [Online]. (cited 2017 March). Available from: http://www.who.int/respiratory/copd/definition/en/.

5. Global strategy for the diagnosis, management and prevention of chronic obstructive pulmonary disease. [Online].;2017 (cited 2017 March). Available from: http://goldcopd.org/gold-2017-global-strategydiagnosis-management-prevention-copd/

6. Veettil SK, Rajiah K, Kumar S. Study of Drug Utilization Pattern for Acute Exacerbation of Chronic Obstructive Pulmonary Disease in Patients Attending a Government Hospital in Kerala, India. Journal of Family Medicine and Primary Care., 2014;3(3):2504.

7. Global initiative for chronic obstructive pulmonary disease updated 2017. Available from: http:// www.goldcopd.org

Cite this article as: Vyas AY, Dumra GH, Singh AJ. Drug utilization study in patients of COPD in TB and Chest department in a tertiary care teaching hospital. Int J Basic Clin Pharmacol 2017;6:1410-3. 